\title{
Efficacy and safety of tenofovir disoproxil fumarate in patients with chronic hepatitis B
}

\author{
Andrés Duarte-Rojo and E. Jenny Heathcote
}

\begin{abstract}
Chronic hepatitis B (CHB) is prevalent worldwide. It may cause cirrhosis and hepatocellular carcinoma. Treatment for this condition may need to be lifelong, thus the drugs used must be both efficacious and safe. Clinical trials of tenofovir have demonstrated a good safety profile for this drug and it has potent antiviral properties. However, to better characterize the safety of this drug, the postmarketing surveillance must be taken into account. Clinicians need to be vigilant, as infrequent adverse events may be revealed during this phase. The current review presents a detailed exposé of preclinical and clinical data on tenofovir to increase awareness of possible adverse events and drug-drug interactions, based on the large experience of this drug in human immunodeficiency virus (HIV) treatment (and to date in patients with $\mathrm{CHB}$ ). Several recommendations that may help the clinician to prevent the development of adverse events associated with tenofovir disoproxil fumarate (TDF) treatment are outlined, along with a suggested surveillance protocol for the timely and proper identification of possible renal and bone toxicity.
\end{abstract}

Keywords: adverse drug event, drug interactions, hepatitis B virus, hypophosphatemia, mitochondrial toxicity, osteomalacia, tenofovir, treatment outcome

\section{Introduction}

It is estimated that 400 million people worldwide are affected by chronic hepatitis B virus (HBV) infection (CHB). The prevalence of HBV infection and its proclivity for a complicated course of disease vary widely according to the geographic area of study, sex, age of acquisition, and likelihood of viral mutations [Dienstag, 2008]. In North America and Western Europe the prevalence of HBsAg in cross-sectional studies is $0.3-1.5 \%$ [Weinbaum et al. 2009; DehesaViolante and Nuñez-Contreras, 2007; Zhang et al. 2001], whereas in some regions of Asia and Africa it reaches $9-12 \%$ of the population [Weinbaum et al. 2009]. Overall, it is assumed that up to $40-50 \%$ of patients with CHB will develop life-threatening complications such as cirrhosis, end-stage liver disease and hepatocellular carcinoma [McMahon, 2009]. The risk of liver-related mortality in CHB is 22 times that of the general population [Duberg et al. 2008].

The prolonged viral suppression needed to achieve loss of serum viral markers of infection (HBeAg and HBsAg) and the likely lifetime persistence of covalently closed circular DNA
(cccDNA) within infected hepatocytes means that treatment of $\mathrm{CHB}$ often needs to be long-term, if not lifelong in some cases [Feld et al. 2009]. Bearing this in mind, the need for an efficacious and safe drug cannot be overemphasized. Hence, the ideal drug must have potent antiviral activity, a high genetic barrier conferring no or low antiviral resistance, has to be well tolerated and lack significant toxicity of any kind. Nowadays there are seven agents approved in several countries for the treatment of $\mathrm{CHB}$, and in the light of the latest results in CHB therapy (including ongoing trials), tenofovir disoproxil fumarate (TDF) stands out as being both efficacious and having a favorable safety profile [Dienstag, 2008].

In this review we will discuss the available information from clinical trials about efficacy and safety of TDF for the treatment of CHB, and make a critical analysis of data obtained from drug development. Experience from reports of TDF for human immunodeficiency virus (HIV) treatment will also be discussed. The intention of this detailed exposé aims to increase the awareness of clinically significant adverse events that
Ther Adv Gastroenterol (2010) 3(2) 107-119 DOI: 10.1177/ 1756283X09354562

(C) The Author(s), 2010. Reprints and permissions: http://www.sagepub.co.uk/ journalsPermissions.nav

Correspondence to: E. Jenny Heathcote Liver Centre, Toronto Western Hospital, University Health Network / University of Toronto. Toronto, Ontario, Canada jenny.heathcoted utoronto.ca

Andrés Duarte-Rojo Liver Centre, Toronto Western Hospital,

University Health Network / University of Toronto. Toronto, Ontario, Canada 
may be observed in the future, now that the postmarketing era of TDF has started. Hopefully this review might help to foresee some potential issues so as to guide its proper use in the treatment of $\mathrm{CHB}$.

\section{The drug approval process and postmarketing surveillance}

The pathway from drug development to new drug delivery to treating physicians and their patients takes many years and has many hurdles. During the preclinical phase a thorough understanding of the pharmacology and toxicity profile of each drug is required, basically through experimental studies on cells, tissues and animals [Stevens and Baker, 2009]. Those drugs that are shown to be potentially safe and efficacious must then be registered with several worldwide regulatory agencies (i.e. FDA) so as to be able to fulfil the requirements enforced for initiating clinical trials (phases I through III). During these phases the investigational new drugs (IND) are tested in humans under ideal and controlled conditions, gathering an exposure experience that, although robust, only comprises several hundreds or at best a few thousands of patients. After completion of phase III randomized clinical trials (RCT) demonstrating both efficacy and safety, approval of new drug application (NDA) is required for the drug to be marketed [Giering and Smith, 1995]. However, this well-rounded system of drug development is not without flaws, and during the postmarketing era, some issues may bring uncertainty to the by then established data. Upon free access of the drug to any physician and patient, the drug exposure experience rises dramatically (reaching tens to hundreds of thousands of patients, within a heterogeneous and uncontrolled environment that may reveal albeit infrequent adverse events, which could have been missed in clinical trials due to the relatively small number of patients required to allow licensing, and restricted patient populations studied [Fletcher and Fletcher, 2005]. Especially for safety purposes, the appropriate ascertainment of a drug profile requires the assessment of the postmarketing surveillance data [Kaplowitz, 2001].

\section{Characterization of TDF: preclinical phase}

\section{Mechanism of action}

TDF is the oral prodrug of tenofovir, with antiviral activities against $\mathrm{HBV}$ and HIV. This acyclic nucleoside phosphonate (i.e. nucleotide) is an analogue of adenosine 5'-monophosphate that inhibits the activity of HBV DNA polymerase by competing with the natural substrate, terminating DNA chain elongation, and therefore, ceasing viral genome replication [Delaney et al. 2006]. It is a very weak inhibitor of mammalian DNA polymerases $\alpha, \beta$, and mitochondrial DNA polymerase $\gamma$, which may explain its favourable cytotoxicity profile [De Clercq and Holy, 2005; Lee et al. 2003].

\section{Pharmacokinetics}

The oral bioavailability of TDF ranges between $25 \%$ and $40 \%$ (depending on the amount of fat in meals), with a serum and intracellular half-life of 17 and 10-50 hours, respectively. Over $90 \%$ of the drug circulates unbound to proteins, and it is eliminated unchanged in the urine via glomerular filtration and tubular secretion. As a consequence, its dosing has to be adjusted once the creatinine clearance is $\leq 50 \mathrm{ml} / \mathrm{min}$. In the proximal renal tubules, the drug is secreted by the orchestrated action of the human organic anion transporters (hOAT1 and 3), from plasma to the tubular cell, and the multiple drug resistant (MDR4) apical efflux pump, from the tubular cell to the tubular lumen [Izzedine et al. 2005]. TDF does not undergo hepatic metabolism for its elimination, so it is not affected by hepatic impairment and can be safely administered to patients with impaired liver function [Viread, 2008].

\section{Pharmacologic interactions and toxicology}

Since TDF has no clinically relevant interaction with the P450 drug metabolising enzyme system, the potential of drug-drug interactions is likely to be low [Viread, 2008]. Proven and potential drug-drug interactions to date are shown in Table 1. Because of its renal elimination pathway, any drug that impairs renal function or competes for active renal tubular secretion can increase its concentration and hence potentiate TDF toxicity (i.e. antiherpetics, including cidofovir).

In pregnancy, the FDA category assigned to TDF is $\mathrm{B}$, as animal studies have not shown any risk, although well-controlled human studies are lacking. Pharmacokinetic studies in pregnant women with HIV have confirmed that TDF crosses the placental barrier, with a transfer rate of $\sim 60 \%$ [Hirt et al. 2009]. However, human registries seem to indicate that the drug is safe, with a rate of birth defects that is similar to the general population [Brown et al. 2009]. Experiments in newborn and infant Rhesus Macaques have disclosed 
Table 1. Reported changes in pharmacokinetics according to drug-drug interactions involving tenofovir disoproxil fumarate.

\begin{tabular}{l}
\multicolumn{3}{c}{ Drug changes during interaction ${ }^{1}$} \\
\hline $\begin{array}{l}\text { Coadministered } \\
\text { drug }\end{array}$
\end{tabular}

that in the short-term ( $\leq 3$ months) TDF does not cause any significant toxicity, but with a prolonged regimen ( $\geq 4$ months) it causes growth restriction, bone deformities (hypophosphatemic ricketts) and renal tubular dysfunction. It is noteworthy that the doses administered to these animals were more than 18 -fold higher than the regular dose approved for use in humans, and the lesions were largely reversible upon discontinuation of the drug [Van Rompay et al. 2004]. As a result, it seems that TDF is safe when data on short-term perinatal exposure at the regular dose is considered, but there are no studies assessing the long-term effects of exposed mothers and infants [Foster et al. 2009]. Based on animal studies, it is presumed that TDF can be secreted in breast milk, therefore breastfeeding of infants is not recommended, as the effects of TDF exposure on neonates or infants are unknown. Studies on carcinogenesis, mutagenesis and fertility, whether in vitro or in animals, with doses over five times that seen in humans on standard doses of TDF have not shown any consistent adverse findings that raise concern for humans [Viread, 2008].

\section{Clinical trials of TDF for chronic hepatitis B}

Although the ultimate goal of treatment in CHB is eradication of the infectious agent, this is rarely, if ever achieved within the liver, because HBV DNA in the form of cccDNA is present in hepatocytes. Consequently, several intermediate or surrogate outcomes have been used as endpoints: alanine aminotransferase (ALT) normalization, HBV DNA suppression, $\mathrm{HBeAg}$ seroconversion. These have shown more or less reliability to predict clinically relevant events, such as the prevention of cirrhosis, end-stage liver disease and hepatocellular carcinoma. Some of the more common and better-characterized endpoints are shown in Table 2. HBsAg loss and seroconversion are to date the best endpoints heralding durable immune control of the virus [Feld et al. 2009].

There are not many phase I/II clinical trials with TDF specifically in CHB, as the information needed came from the numerous studies of TDF in HIV. These studies established the basis for the treatment of monoinfected patients with $\mathrm{HBV}$ and contributed data regarding the safety profile of TDF in these patients. As early as 2003 case descriptions of patients 'salvaged' from lamivudine-resistant HBV with TDF were published [Kuo et al. 2004; van Bömmel et al. 2003]. Later, two pilot studies (including at least 20 patients) strengthened the clinical application of TDF in patients with lamivudine-resistant $\mathrm{CHB}$, and indicated that TDF was more effective than adefovir, and that it may be effective even in cases that had failed adefovir therapy [Tan et al. 2008; van Bömmel et al. 2004, 2006].

Currently there are two ongoing multicenter phase III trials (double-blind RCT for the first year only) and the outcomes after the first 48 weeks have been published [Marcellin et al. 2008]. In Study 103, a total of $266 \mathrm{HBeAg}(+)$ patients received either TDF $(n=176)$ or adefovir $(n=90)$, while in Study $102,375 \mathrm{HBeAg}(-)$ patients were randomized to receive either TDF $(n=250)$ or adefovir $(n=125)$. Patients may have received treatment with other nucleos(t)ide drugs. The main endpoint was a combined virologic and histologic response (HBV DNA $<69 \mathrm{IU} / \mathrm{ml}$ and a reduction in $\geq$ two points in Knodell necroinflammatory score without an increase in fibrosis). Significant differences in this combined outcome favoring TDF were observed in both studies. The proportion of patients with undetectable $\mathrm{HBV}$ DNA was $76 \%$ for TDF and $13 \%$ for adefovir in $\mathrm{HBeAg}(+)$ patients; and $93 \%$ and $63 \%$, 
Table 2. Possible endpoints for the treatment of chronic hepatitis B infection.

\begin{tabular}{|c|c|c|c|}
\hline Criteria & Description & Endpoint & Clinical significance \\
\hline $\begin{array}{l}\text { Biochemical } \\
\text { Serological } \\
\text { Virological } \\
\text { Histological }\end{array}$ & $\begin{array}{l}\text { ALT/AST } \\
\text { HBeAg } \\
\text { HBsAg } \\
\text { HBV DNA } \\
\text { Grading (inflammation) } \\
\text { Staging (fibrosis) }\end{array}$ & $\begin{array}{l}\text { Normalization } \\
\text { HBeAg loss } \pm \text { anti-HBe } \\
\text { HBsAg loss } \pm \text { anti-HBs } \\
\text { Suppression } \\
\text { Improvement ( } \geq 1-2 \text { points) } \\
\text { Improvement or no increase }\end{array}$ & $\begin{array}{l}\text { Not specific to HBV } \\
\text { Favorable } \\
\text { Excellent prognosis }^{2} \\
\text { Favorable on-treatment } \\
\text { Accurate and relevant }\end{array}$ \\
\hline \multicolumn{4}{|c|}{$\begin{array}{l}\text { ALT, alanine aminotransferase; AST, aspartate aminotransferase. } \\
{ }^{1} \text { Only useful in } \mathrm{HBel}+(\mathrm{CHC} \text { and if maintained off-treatment. Seroconversion (anti-HBe) gives an even better prognosis. } \\
{ }^{2} \text { Particularly if this occurs in patients before age } 50 \text {. Seroconversion (anti-HBs) gives an even better prognosis. } \\
{ }^{3} \text { Using sensitive assays }(<100 \mathrm{UI} / \mathrm{ml} \text { l. } \\
{ }^{4} \text { Usually one-point decrease when using the Metavir system, or two-point with Knodell or Ishak scales. } \\
\text { Copyright (2009) Wiley. Used with permission from Feld et al. [2009] Endpoints of therapy in chronic hepatitis B. } \\
\text { Hepatology; 49: 96-102. }\end{array}$} \\
\hline
\end{tabular}

respectively, for the $\mathrm{HBeAg}(-)$ group. In the TDF groups no difference was found between patients previously treated with lamivudine and those that had not received this drug. The rate of $\mathrm{HBeAg}$ loss was $21 \%$ for TDF and $18 \%$ for adefovir, a nonsignificant difference. HBsAg was lost in five patients $(3.2 \%)$ treated with TDF within the $\mathrm{HBeAg}(+)$ group [Marcellin et al. 2008]. Further follow-up of Study 103 for 96 weeks has shown that TDF treatment was able to maintain suppressed HBV DNA levels in $78 \%$ of patients, while in those originally randomized to adefovir, all of whom were switched to TDF at week 48, a HBV DNA suppression rate of $82 \%$ was observed. The cumulative $\mathrm{HBeAg}$ seroconversion and HBsAg loss were $22-27 \%$ and $6 \%$, respectively (the latter limited to only those $\mathrm{HBeAg}(+)$ at baseline). Greater than $80 \%$ of the original patients recruited to this trial remained on TDF therapy up until week 96 [Heathcote et al. 2008].

In coinfected patients with HBV and HIV the information regarding TDF is rather heterogeneous, and data on efficacy derived from controlled trials is scarce. Analysis of cohorts which have included at least 20 patients with HBV-HIV suggest that TDF containing regimens can suppress HBV DNA levels in the majority of patients [Lacombe et al. 2008; Jain et al. 2007; Benhamou et al. 2006; Schmutz et al. 2006; Stephan et al. 2005; Nelson et al. 2003], with loss of HBeAg ranging from $6 \%$ to $40 \%$ after 1 year of treatment [Lacombe et al. 2008; Jain et al. 2007; Stephan et al. 2005], and has been shown to be as effective in naïve as in lamivudine-resistant CHB [Schmutz et al. 2006]. These studies have failed to identify any differences when TDF is administered alone or with lamivudine [Schmutz et al. 2006]. As a result, effectiveness of treatment seems to be similar to that reported in monoinfected patients, and some of the factors identified as being associated with nonresponse are poor compliance, non-A genotype, ongoing HIV therapy [Jain et al. 2007], and lack of immunological response to antiretroviral therapy [Nuñez et al. 2006; Benhamou et al. 2006]. However, no randomized trial employing TDF has compared the efficacy in coinfected versus monoinfected patients.

Peters et al. [2006] conducted a double-blind RCT comparing 27 patients with TDF against 25 on adefovir, most being $\mathrm{HBeAg}(+)$ with stable HIV disease. They found a higher proportion of patients attained undetectable HBV DNA at 48 weeks with TDF $(20 \%)$ than with adefovir $(6 \%)$, but the difference did not reach statistical significance using their noninferiority design. Only one patient in the adefovir group lost HBeAg (4\%). Matthews et al. [2008] in a nonblinded RCT demonstrated neither a significant superiority of two antiretroviral regimens containing TDF (11 patients with lamivudine and 12 without it) versus a regimen with lamivudine as the only anti-HBV drug (13 patients). The proportion of patients with undetectable HBV DNA after 48 weeks of therapy for each group was $64 \%$, $75 \%$ and $46 \%$, respectively. The rate of $\mathrm{HBeAg}$ loss for TDF regimens was $17 \%$ and $43 \%$, while for lamivudine it was $33 \%$. The rate of HBsAg loss was $8 \%$ in the three arms of this study. Therefore, in these small and underpowered clinical trials, superiority of TDF or dual therapy of TDF and lamivudine could not be ascertained.

\section{Antiviral resistance}

Another major issue related to efficacy of any drug used in the treatment of CHB is the development of resistant strains of $\mathrm{HBV}$. In vitro studies have 
disclosed the development of certain mutations that may confer decreased susceptibility to TDF [Delaney et al. 2006; Brunelle et al. 2005]. The clinical relevance of these mutations is dubious, although in a few cases, evidence for cross-resistance with adefovir-resistant mutations has been observed [Tan et al. 2008]. Resistance surveillance in Studies 102 and 103 during the 96 weeks of treatment have shown that, five out of ten patients with virological breakthrough (defined as an increase $\geq 1 \log _{10}$ from nadir or confirmed HBV DNA $\geq 69 \mathrm{UI} / \mathrm{ml}$ after having been $<69 \mathrm{UI} / \mathrm{ml}$ ) developed different polymorphic site changes in $\mathrm{HBV}$ polymerase. However, some of these polymorphisms were common at baseline and therefore not related to virologic breakthrough, while the others did not affect response to TDF in vitro. Conserved site changes, only identified in four patients, were not accompanied by virologic breakthrough. The main factor associated with breakthrough was a history of noncompliance [Marcellin et al. 2008; Snow-Lampart et al. 2008]. Regarding patients with HBV-HIV coinfection, genotypic analyses of 43 TDFexperienced patients showed a decrease in the in vitro response [Sheldon et al. 2005]. However, the genotypic variations in $\mathrm{HBV}$ polymerase identified at baseline in several studies have not been associated with phenotypic resistance to TDF; rather, coadministration of TDF and lamivudine can suppress the development of mutations conferring resistance to the latter [Matthews et al. 2008; Jain et al. 2007; Benhamou et al. 2006; Nuñez et al. 2006; Peters et al. 2006]. Although not thoroughly studied, the available evidence implies that there is no difference in the genetic barrier of TDF against HBV between monoinfected and coinfected patients.

\section{Safety of TDF}

The classification of the severity of drug-related adverse events is complex. A simplified approach to clinical and some laboratory parameters is shown in Tables 3 and 4 . In one of the large registration trials of TDF for HIV (Study 907) in which patients who were antiretroviral experienced were randomized to either TDF or placebo, the more frequent grade 2-4 adverse events $(\geq 3 \%)$ observed were: diarrhea $(11 \%)$, nausea $(8 \%)$, asthenia, pain $(7 \%)$, headache, a rash event $(5 \%)$, vomiting, abdominal pain and depression (4\%); while the more frequent grade 3-4 laboratory abnormalities (see Table 4) were: elevated triglycerides $(8 \%)$, creatine kinase $(7 \%)$, serum amylase (6\%), ALT/AST (4\%), and glucose $(3 \%)$; and glucosuria (3\%). However, these reactions did not occur more frequently than in patients randomized to placebo [Viread, 2008]. In the two RCTs in monoinfected patients with CHB (Studies 102 and 103) nausea was the only adverse event that occurred more frequently in TDF than in adefovir-treated patients (9\% versus $3 \%$ ), although only in one case it was grade 2 (grade 1 in the others). Other common $(\geq 3 \%)$ adverse events observed in patients on TDF were: headache (13\%), nasopharyngitis $(10 \%)$, fatigue $(8 \%)$, abdominal pain, back pain, diarrhea (7\%), and dizziness (6\%). The most common grade 3-4 laboratory abnormalities (see Table 4) reported were: increase in ALT and aspartate aminotransferase (AST) (up to $10 \%)$, serum amylase $(4 \%)$, and glycosuria $(3 \%)$. Elevated creatine kinase was observed in $2 \%$. Hepatitis flares (grade 4 in $3 \%$ ) occurred early in the course of the trial (first 8 weeks), resolved spontaneously without adjustment in TDF, did not lead to hepatic decompensation and were associated with a decrease in HBV DNA levels. TDF was discontinued because of fatigue and other uncommon adverse effects in five patients $(1 \%)$, in none were they considered severe [Marcellin et al. 2008]. Increases in serum creatinine $(>0.5 \mathrm{mg} / \mathrm{dl}$ above baseline) and grade 2 hypophosphatemia (see Table 4) have been described in less that $1 \%$ of patients after a follow-up of 96 weeks. Nevertheless, the effect of TDF is confounded by the fact that all of these cases were originally randomized to adefovir and switched to TDF after 48 weeks [Heathcote et al. 2008]. Pilot studies neither reported an increase in serum creatinine levels or change in phosphate levels [van Bömmel et al. 2006, 2004]. Not a single case of renal tubular dysfunction has been reported in the literature.

Regarding adverse effects in the HBV-HIV coinfected population, at least two issues which could potentially affect safety require special attention: a higher rate of hepatitis flares presumably as consequence of immune reconstitution, as well as an increased risk of drug-related toxicity caused by antivirals alone or when combined with other antimicrobials. Hepatitis flares were identified in 21-25\% of patients [Matthews et al. 2008; Peters et al. 2006], but were not associated with changes in synthetic function, except for one patient who developed rapid hepatic decompensation and died [Matthews et al. 2008]. In some cases, flares were followed by HBeAg seroconversion [Matthews et al. 2008]. 
Table 3. Categories for estimating the severity of adverse events related to drugs.

\begin{tabular}{|c|c|c|c|c|}
\hline & Grade 1 mild & Grade 2 moderate & Grade 3 severe & Grade 4 life-threatening \\
\hline $\begin{array}{l}\text { Interference of usual } \\
\text { social and functional } \\
\text { activities }{ }^{1}\end{array}$ & No or minimal & $\begin{array}{l}\text { Greater than } \\
\text { minimal }\end{array}$ & Total & $\begin{array}{l}\text { Inability even to } \\
\text { perform basic } \\
\text { self-care functions }\end{array}$ \\
\hline Medical intervention/therapy & Not required & $\begin{array}{l}\text { Not required } \\
\text { or minimal }\end{array}$ & $\begin{array}{l}\text { Required. Possible } \\
\text { hospitalization }\end{array}$ & $\begin{array}{l}\text { Indicated to prevent } \\
\text { permanent impairment, } \\
\text { persistent disability or death. }\end{array}$ \\
\hline
\end{tabular}

Table 4. Grading of the severity of adverse events related to drugs: laboratory parameters.

\begin{tabular}{lllll}
\hline & Grade 1 & Grade 2 & Grade 3 & Grade 4 \\
\hline Amylase & $1.1-1.5 \times$ ULN & $1.6-2 \times$ ULN & $2.1-5 \times$ ULN & $>5 \times$ ULN \\
ALT or AST & $1.25-2.5 \times$ ULN & $2.6-5.0 \times$ ULN & $5.1-10 \times$ ULN & $>10 \times$ ULN \\
Creatine kinase & $3-5.9 \times$ ULN & $6-9.9 \times$ ULN & $10-19.9 \times$ ULN & $\geq 20 \times$ ULN \\
Creatinine & $1.1-1.3 \times$ ULN & $1.4-1.8 \times$ ULN & $1.9-3.4 \times$ ULN & $\geq 3.5 \times$ ULN \\
Glucose (high) & $6.11-6.94 \mathrm{mmol} / \mathrm{l}$ & $6.95-13.88 \mathrm{mmol} / \mathrm{l}$ & $13.89-27.75 \mathrm{mmol} / \mathrm{l}$ & $>27.75 \mathrm{mmol} / \mathrm{l}$ \\
& $110-125 \mathrm{mg} / \mathrm{dl}$ & $126-250 \mathrm{mg} / \mathrm{dl}$ & $250-500 \mathrm{mg} / \mathrm{dl}$ & $>500 \mathrm{mg} / \mathrm{dl}$ \\
Phosphate (low) & LLN-0.81 mmol/l & $0.80-0.65 \mathrm{mmol} / \mathrm{l}$ & $0.64-0.32 \mathrm{mmol} / \mathrm{l}$ & $<0.32 \mathrm{mmol} / \mathrm{l}$ \\
& LLN-2.5 mg/dl & $2.4-2.0 \mathrm{mg} / \mathrm{dl}$ & $1.9-1 \mathrm{mg} / \mathrm{dl}$ & $<1 \mathrm{mg} / \mathrm{dl}$ \\
\hline \multirow{2}{*}{ ALT, alanine aminotransferase; AST, aspartate aminotransferase; ULN, upper limit of normal; LLN, lower limit of normal. } \\
Courtesy: National Institute of Allergy and Infectious Diseases [NIAID, 2004].
\end{tabular}

It is noteworthy that in both trials the definition of a flare of hepatitis B required elevation in ALT (three to five times the upper limit of normal, or $>100 \mathrm{IU} / \mathrm{ml}$ from baseline if elevated) below that recommended by FDA ( $>10$ times the upper limit of normal). Studies 903 and 907 reported that $3 / 15(20 \%)$ patients within their subsets with coinfection, developed grade 3-4 ALT elevations as isolated abnormalities not leading to hepatic decompensation [Dore et al. 2004].

In the RCT of HBV-HIV coinfected patients no derangement in the levels of serum creatinine was noted after 48 weeks of treatment [Matthews et al. 2008; Peters et al. 2006], but in one trial $3 / 27(11 \%)$ cases with TDF developed grade 2 hypophosphatemia, and 3 patients had at least one episode of acute pancreatitis (2 while on didanosine, allocation not specified) [Peters et al. 2006]. Differences between the arms of treatment for each study were not reported. One case of renal tubular dysfunction, occurring in a patient with concomitant non-Hodgkin lymphoma that presented as Fanconi-like syndrome, was reported in a cohort of 54 patients. The renal disorder resolved within a few weeks of TDF withdrawal [Benhamou et al. 2006]. There may have been untoward drug-drug interactions which promoted these unfavorable events.

\section{Lessons to learn from the HIV experience}

\section{Mitochondrial toxicity}

Most of the severe adverse effects associated with antivirals used to treat HIV patients derive from what is known as mitochondrial toxicity. This occurs because nucleos(t)ide analogues are incorporated into the human mitochondrial DNA (mtDNA) polymerase- $\gamma$, causing energy decline, oxidative stress, and ultimately mtDNA mutations [Lee et al. 2003]. Clinical correlates of mitochondrial toxicity are: lactic acidosis, fat redistribution syndrome, hepatic steatosis, acute pancreatitis, proximal renal tubular dysfunction, myopathy, and peripheral neuropathy [Moyle, 2005]; and some of these were not identified until the postmarketing period of TDF. Many factors can influence this toxicity but enzymatic studies have disclosed that the drugs used to treat CHB (i.e. TDF and lamivudine) have extremely low indices of mtDNA toxicity, when compared with other nucleoside reverse transcriptase inhibitors used to treat HIV (i.e. nucleoside reverse transcriptase analogues or NRTI, such as 
zalcitabine, didanosine, stavudine) [Lee et al. 2003]. Studies in animals and in vitro have failed to demonstrate TDF-associated mtDNA toxicity [Venhoff et al. 2007; Biesecker et al. 2003; Birkus et al. 2002]. Also, evidence on the improvement of the fat redistribution syndrome upon change from stavudine to TDF has been reported [Ananworanich et al. 2008].

Current evidence makes it impossible to be adamant that TDF does not play a role in mtDNA toxicity. It is tempting to assume that most of these toxicities are the result of complex drug interactions in vulnerable patients infected with HIV, as it has been noted that untreated HIV can also exert mtDNA toxicity [Moyle, 2005]. Accordingly, the rates of some of these complications (increases in serum amylase and creatine kinase) in the trials of TDF have been less in those treated for CHB versus those with just HIV; and no cases of lactic acidosis, fat redistribution syndrome, hepatic steatosis, and peripheral neuropathy have been reported in the former. Nevertheless, caution is advised with TDF administration, and especially when other drugs that can also potentially cause mtDNA toxicity are used concomitantly. A list of some of these drugs/substances is shown in Box 1.

\section{Proximal renal tubular dysfunction}

After the good renal safety profile identified in the registration studies of TDF for the treatment of HIV [Gallant et al. 2004; Squires et al. 2003; Schooley et al. 2002], cases of acute renal failure in patients receiving TDF begun to appear in the medical literature, some associated with the Fanconi syndrome (urinary loss of amino acids, glucose, uric acid, phosphorus, bicarbonate and low molecular weight proteins) and nephrogenic diabetes insipidus [Creput et al. 2003; Karras et al. 2003; Verhelst et al. 2002; Coca and Perazella, 2002]. A review of the adverse events reported to FDA after the first 5 years of TDF approval for the treatment of HIV identified 164 cases of Fanconi syndrome, although this publication was limited by the inaccuracies of spontaneous reporting of cases and lack of validation of the submitted reports. The majority of these patients had received protease inhibitors as part of their HIV therapy, primarily ritonavir-boosted regimens, or had had didanosine co-prescribed [Gupta, 2008]. In prospective studies, three cases of Fanconi syndrome out of 154 patients (2\%), and five with severe renal injury in a series of 40 patients (13\%) have been identified; along with a rate of
Box 1. Compounds that could potentially cause mitochondrial DNA toxicity if administered along with tenofovir disoproxil fumarate.

Acyclovir (long-term)
Isoniazid
Alcohol
Other nucleos(t)ide analogues ${ }^{1}$
Amiodarone
NSAIDs
Amphetamines
Metformin
Anthracyclines
Ribavirin
Atenolol
Rosiglitazone
Flutamide
Valproic acid
Interferon- $\alpha$
Tamoxifen
NSAIDs, nonsteroidal anti-inflammatory drugs.
${ }^{1}$ Including nucleoside reverse transcriptase inhibitors
(NRTI) [Dhillon et al. 2008; Dykens and Will, 2007;
Hanes et al. 2007; Moyle, 2005].

hypophosphatemia of $10 \%$ (all grade 1, except for one patient with grade 2) [Kinai and Hanabusa, 2009; Labarga et al. 2009; Essig et al. 2007]. Two of these three studies were controlled and identified impairment in renal phosphate transport (whether alone or in association with other abnormalities such as tubular proteinuria) in $22 \%$ and $45 \%$ of patients on TDF, a significantly higher proportion than that observed in the controls in either study [Kinai and Hanabusa, 2009; Labarga et al. 2009]. The lower rate of hypophosphatemia than hyperphosphaturia has suggested that some patients may develop isolated hyperphosphaturia because of the compensating effect of increased bone resorption of phosphate. This raises a concern about possible bone toxicity in patients chronically taking TDF [Essig et al. 2007].

The cause of the renal tubular dysfunction in patients treated with TDF may be secondary to specific mtDNA toxicity within the proximal tubules. This hypothesis is biologically plausible, as TDF is secreted in the proximal renal tubules through a mechanism involving the hOAT- 1 and 3, and the MDR4 efflux pump. Polymorphisms in these transporters or drug interactions could lead to a toxic increase in intracellular concentrations of TDF (presumably promoted by concomitant ritonavir). Although in vitro studies have not supported mtDNA toxicity in proximal renal tubule cells [Vidal et al. 2006], two recent models in animals showed clear evidence for 
this effect [Kohler et al. 2009; Lebrecht et al. 2009]. Kidney biopsies in humans with Fanconi syndrome also suggest mtDNA toxicity within the proximal tubules in some cases [Woodward et al. 2009; Peyriere et al. 2004; Izzedine et al. 2004; Creput et al. 2003; Karras et al. 2003; Coca and Perazella, 2002]. Just as stavudine is known for the development of fat redistribution syndrome and zidovudine for the myopathy it causes [Lee et al. 2003], it has been suggested that proximal renal tubular dysfunction could represent the prominent feature of mtDNA toxicity in patients taking TDF [Bagnis et al. 2009; Gitman et al. 2007]. A group of clinicians with specific expertise in HIV have developed a screening strategy for assessing hypophosphatemia and proximal renal tubular dysfunction while on treatment, so as to identify early and intervene with changes in management [Bagnis et al. 2009].

\section{Bone toxicity}

Isolated cases of osteomalacia have been reported in the literature occurring in HIV patients treated with TDF complicated by the Fanconi syndrome [Perrot et al. 2009; Torres-Isidro et al. 2006; Parsonage et al. 2005; Earle et al. 2004]. Prospective studies in HIV patients given a TDF-containing antiretroviral regimen looked for bone abnormalities in patients with proximal renal tubular dysfunction. Both osteomalacia and osteopenia (12 out of 22, and four out of 90 patients, respectively) were observed [Woodward et al. 2009; Essig et al. 2007]. The prevalence of these bony complications are so far unknown, as these cohorts represent highly selected populations, and there was a clear referral-bias in one study [Woodward et al. 2009]. Increases in serum levels of alkaline phosphatase while on TDF have been described, presumably from enhanced bone turnover [Kinai and Hanabusa, 2009], even in the absence of renal abnormalities [Fux et al. 2008]. These findings suggest that this complication may occur even without florid proximal renal tubular dysfunction. Prospective studies specifically assessing bone content and renal tubular function are required.

\section{HBV versus HIV: two different clinical scenarios}

Although efficacy of TDF seems to be similar between HBV monoinfected and HBV-HIV coinfected patients, it is expected that the context of the safety of TDF in patients with just CHB may be unlike those with HIV. Frequently patients with HIV end up on multiple drugs [i.e. use of several antivirals and antimicrobials, nonsteroidal anti-inflammatory drugs (NSAIDs)], which significantly increase the chances of having an adverse drug reaction. With regard to potential kidney damage, apart from drug-associated toxicity and some complex drug interactions that have been reported, HIV infection is associated with a variety of glomerulopathies not observed in patients being treated with TDF for CHB. Perhaps also relevant is that opportunistic infections do not occur in CHB and associated conditions such as atherosclerotic diseases are much more infrequent in CHB than in HIV/AIDS [Cho and Kopp, 2004].

The coexistence of several factors related to disease and adverse drug effects make it difficult to directly apply the experience of TDF in HIV to that of $\mathrm{CHB}$ in monoinfected patients. The unique case of proximal renal tubular dysfunction in CHB was reported in a patient with concomitant treated HIV who also had non-Hodgkin lymphoma [Benhamou et al. 2006]. Nevertheless, close observation must be maintained when TDF is used for treatment of CHB. Some of the complications witnessed in patients with HIV were only observed during the postmarketing era (i.e. proximal renal tubular dysfunction). By no means is it suggested that a parallel evolution will occur in CHB monoinfection, but heightened awareness allowing for timely intervention is advocated.

\section{Recommendations to avoid toxicity based on the HIV experience}

So as to avoid toxicity in patients with $\mathrm{CHB}$ under treatment with TDF it is necessary to well characterize any coexisting risk for toxicity, especially under circumstances favouring renal injury (older age, diabetes mellitus, atherosclerotic disease, chemotherapy). A dynamic adjustment of the interval of dosing according to creatinine clearance in patients with elevated serum creatinine is of utmost importance (Table 5). It should be remembered that creatinine alone cannot identify subtle changes in renal function, especially in patients with low muscle mass (i.e. the elderly, the sick) in which the glomerular filtration rate is overestimated. Additionally, avoidance of any known drug-drug interaction is recommended (Table 1), and in cases in which this is not possible, increasing the closeness of follow-up with 
Table 5. Suggested dosing interval recommendations for tenofovir disoproxil fumarate according to creatinine clearance.

\begin{tabular}{|c|c|}
\hline $\mathrm{CrCl}^{1}$ & Interval \\
\hline $\begin{array}{l}\geq 50 \mathrm{ml} / \mathrm{min} \\
49-30 \mathrm{ml} / \mathrm{min} \\
29-10 \mathrm{ml} / \mathrm{min} \\
\text { Hemodyalisis }\end{array}$ & $\begin{array}{l}\text { Every } 24 \mathrm{~h} \\
\text { Every } 48 \mathrm{~h} \\
\text { Every } 72-96 \mathrm{~h} \\
\text { After cumulating } \\
\quad 12 \text { hours of procedure }\end{array}$ \\
\hline \multicolumn{2}{|c|}{$\begin{array}{l}{ }^{1} \mathrm{CrCl} \text {, creatinine clearance, calculated with ideal (lean) } \\
\text { bodyweight using Cockroft-Gault equation. } \\
{ }^{2} \text { This translates into every } 7 \text { days, assuming a mainte- } \\
\text { nance hemodyalisis schedule that cumulates } 12 \mathrm{~h} \text { per } \\
\text { week (i.e. thrice-weekly, each session of } \sim 4 \text { hours). } \\
\text { Reproduced from Kearney BP, Yale K, Sha J, Lijie A, } \\
\text { Flaherty JF. Parmacokinetics and dosing recommenda- } \\
\text { tions of tenofovir disoproxil fumarate in hepatic or renal } \\
\text { impairment. Clin Pharmacokinet 2006; } 45: 1115-24 \text {, with } \\
\text { permission from Adis, a Wolters Kluwer business } \\
\text { (@)Adis Data Information BV 2006. All rights reserved). } \\
\text { (Kearney et al. [2006]). }\end{array}$} \\
\hline
\end{tabular}

careful history taking and laboratory tests may allow a timely identification of unexpected complications. Advice from pharmacists is encouraged, and referral to trained specialists should be considered, especially in HBV-HIV coinfected people. Both alcohol and NSAIDs should be discouraged, and the concomitant use of two or more drugs with potential mtDNA toxicity should be used with caution (Table 4). Of course, any symptom reported by patients or abnormalities observed on physical or in laboratory tests should be evaluated in a wider clinical context, although the possibility of TDF toxicity must not be disregarded. A proposed approach for the assessment and follow-up of those patients with CHB that develop renal abnormalities under treatment with TDF is shown in Figure 1.

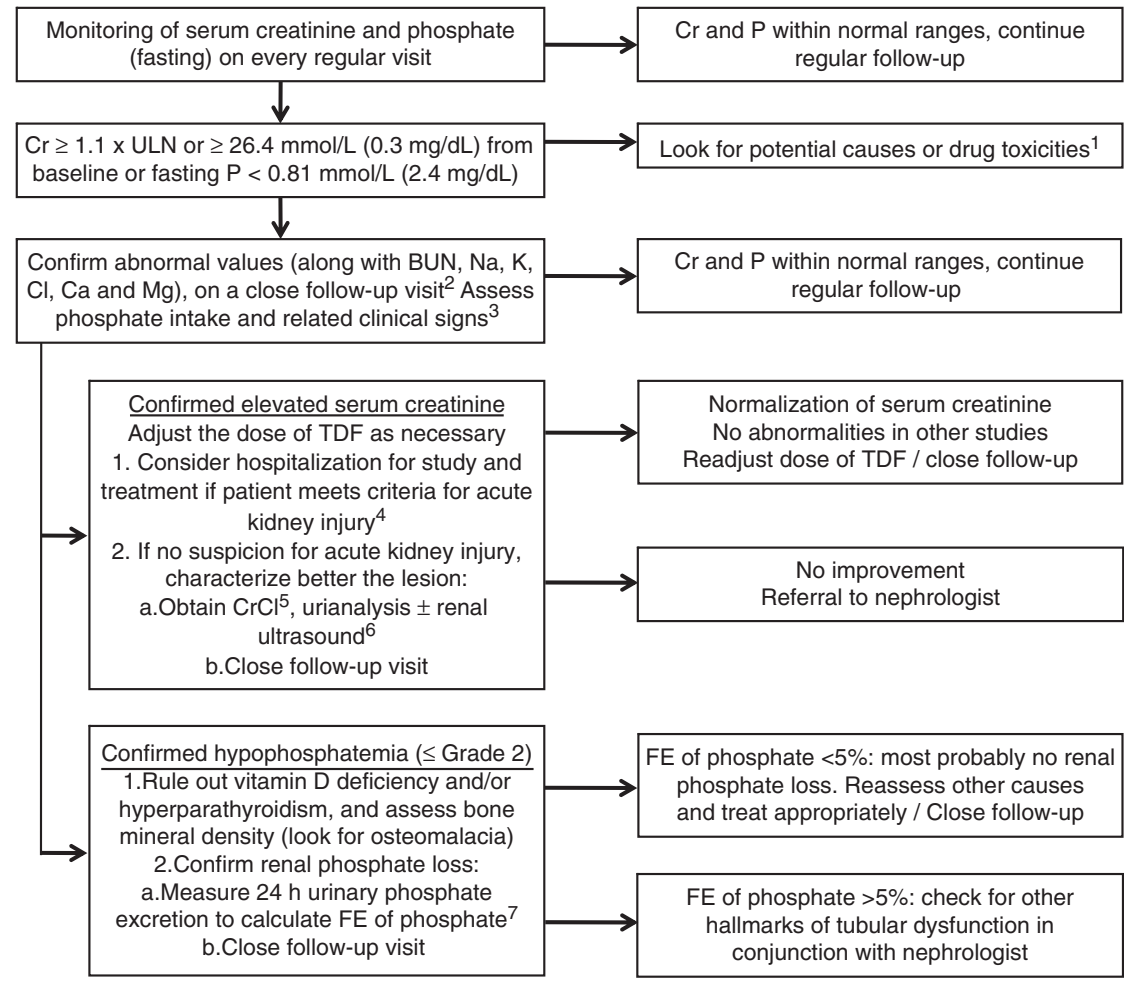

Figure 1. Proposed algorithm for the assessment and follow-up of renal and bone abnormalities potentially associated with tenofovir disoproxil fumarate treatment. BUN, blood urea nitrogen; $\mathrm{Cr}$, serum creatinine, $\mathrm{P}$, phosphate; ULN, upper limit of normal; $\mathrm{CrCl}$, creatinine clearance; FE, fractional excretion; TDF, tenofovir disoproxil fumarate. ${ }^{1} \mathrm{HVB}$-related glomerulonephritis, infection, undernourishment, alcoholism, refeeding syndrome, volume depletion, diarrhea/malabsorption, diuretics, antacids. ${ }^{2}$ If suspicion of acute kidney injury, laboratory tests must be performed within 48 hours. ${ }^{3}$ Poor intake alone is rarely responsible for phosphate depletion, but it is recommended to assess this possibility with a nutriologist. Evident signs may develop if grade 3 or 4 hypophosphatemia occurs, and may include: myopathy, ileus, hemolysis, metabolic encephalopathy, respiratory and congestive heart failure; consider hospitalization. ${ }^{4} \mathrm{According}$ to the Acute Kidney Injury Network. ${ }^{5} \mathrm{CrCl}$ : $\mathrm{creatinine}$ clearance lurinary creatinine $\times$ urine volume / serum creatinine $\times$ time). The usefulness of $\mathrm{CrCl}$ is remarkably reduced in the presence of decompensated cirrhosis and its evaluation is not warranted. ${ }^{6}$ Specially if not assessed previously or when considering postrenal causes. ${ }^{7} \mathrm{FE}$ of phosphate: fractional excretion of phosphate (urinary phosphate $\times$ plasma creatinine / plasma phosphate $\times$ urinary creatinine). [Bagnis et al. 2009; Garcia-Tsao et al. 2008]. 


\section{Conclusion}

The rate of seroconversion (HBeAg and $\mathrm{HBsAg}$ ) when TDF is given in the long-term to subjects with CHB still remains unknown as the rates disclosed so far are premature. However, the data analyzed in this review, viewed within the context of present endpoints of treatment, allows us to suggest that TDF is both efficacious and safe for the treatment of CHB. However, to fully ascertain such a statement does not end with the approval of the NDA, especially when considering the safety profile of TDF used over many years, so monitoring must continue in the postmarketing era and reports made of any evidence of toxicity. It is the responsibility of all physicians to prescribe TDF in line with current recommendations, keeping in mind some of the suggestions outlined herein. Only a responsible and directed surveillance of complications will allow the disclosure of possible unknown adverse effects to the corresponding health authorities.

\section{Acknowledgments}

Andrés Duarte-Rojo receives funding for a Clinical Fellowship from the Instituto de Ciencia y Tecnología del Distrito Federal, ICyTDF (México), and The American College of Gastroenterology, ACG: International Training Grant 2009 (USA).

\section{Conflict of interest statement}

E. Jenny Heathcote receives grant support and/or consulting fees from Axcam Pharma, Boehringer Ingelheim, Bristol-Myers Squib, Debio Pharma, Gilead Sciences, GlaxoSmithKline, HoffmanLaRoche, Human Genome Sciences, Intercept, Merck, Novartis, Schering-Plough, Tibotec and Vertex.

\section{References}

Ananworanich, J., Nuesch, R., Côté, H.C., Kerr, S.J., Hill, A., Jupimai, T. et al. (2008) Changes in metabolic toxicity after switching from stavudine/didanosine to tenofovir/lamivudine-a staccato trial substudy. f Antimicrob Chemother 61: 1340-1343.

Bagnis, C.I., Karie, S., Deray, G. and Essig, M. (2009) Hypophosphatemia: an easy strategy for diagnosis and treatment in HIV patients. Antiviral Ther 14: 1359-1365.

Benhamou, Y., Fleury, H., Trimoulet, P., Pellegrin, I., Urbinelli, R., Katlama, C. et al. (2006) Anti-hepatitis $\mathrm{B}$ virus efficacy of tenofovir disoproxil fumarate in HIV-infected patients. Hepatology 43: 548-555.

Biesecker, G., Karimi, S., Desjardins, J., Meyer, D., Abbott, B., Bendele, R. et al. (2003) Evaluation of mitochondrial DNA content and enzyme levels in tenofovir DF-treated rats, rhesus monkeys and woodchucks. Antiviral Res 58: 217-225.

Birkus, G., Hitchcock, M.J. and Cihlar, T. (2002) Assessment of mitochondrial toxicity in human cells treated with tenofovir: Comparison with other nucleoside reverse transcriptase inhibitors. Antimicrob Agents Chemother 46: 716-723.

Brown Jr, R.S., Buti, M., Goodwin, D., Zhang, S. and Fagan, E. (2009) Hepatitis B virus (HBV) drugs in pregnancy: findings from the antiretroviral pregnancy registry. F Hepatol 50: S4.

Brunelle, M.N., Jacquard, A.C., Pichoud, C., Durantel, D., Carrouee-Durantel, S., Villeneuve, J.P. et al. (2005) Susceptibility to antivirals of a human HBV strain with mutations conferring resistance to both lamivudine and adefovir. Hepatology 41: 1391-1398.

Cho, M.E. and Kopp, J.B. (2004) HIV and the kidney: a status report after 20 years. Curr HIVIAIDS Rep 1: 109-115.

Coca, S. and Perazella, M.A. (2002) Rapid communication: acute renal failure associated with tenofovir: evidence of drug-induced nephrotoxicity. $A m \mathcal{F} \mathrm{Med}$ Sci 324: 342-345.

Creput, C., Gonzalez-Canali, G., Hill, G., Piketty, C., Kazatchkine, M. and Nochy, D. (2003) Renal lesions in HIV-1-positive patient treated with tenofovir. AIDS 17: 935-937.

De Clercq, E. and Holy, A. (2005) Acyclic nucleoside phosphonates: a key class of antiviral drugs. Nat Rev Drug Discov 4: 928-940.

Dehesa-Violante, M. and Nuñez-Nateras, R. (2007) Epidemiology of hepatitis B and C. Arch Med Res 38: 606-611.

Delaney, W.E., Ray, A.S., Yang, H., Qi, X., Xiong, S., Zhu, Y. et al. (2006) Intracellular metabolism and in vitro activity of tenofovir against hepatitis B virus. Antimicrob Agents Chemother 50: 2471-2477.

Dhillon, R., Rossi, S. and Herrine, S.K. (2008) Pegylated interferon $2 \mathrm{a}$ and $2 \mathrm{~b}$ in combination with ribavirin for the treatment of chronic hepatitis $C$ in HIV infected patients. Ther Clin Risk Manag 4: 789-796.

Dienstag, J.L. (2008) Hepatitis B virus infection. $N$ Engl F Med 359: 1486-1500.

Dore, G.J., Cooper, D.A., Pozniak, A.L., DeJesus, E., Zhong, L., Miller, M.D. et al. (2004) Efficacy of tenofovir disoproxil fumarate in antiretroviral therapy-naive and -experienced patients coinfected with HIV-1 and hepatitis B virus. F Infect Dis 189: 1185-1192.

Duberg, A.S., Torner, A., Daviosdottir, L., Aleman, S., Blaxhult, A., Svensson, A. et al. (2008) Cause of death in individuals with chronic HBV and/or HCV infection, a nationwide community-based register study. $\mathcal{F}$ Viral Hepat 15: 538-550. 
Dykens, J.A. and Will, Y. (2007) The significance of mitochondrial toxicity testing in drug development. Drug Discov Today 12: 777-785.

Earle, K.E., Seneviratne, T., Shaker, J. and Shoback, D. (2004) Fanconi's syndrome in HIV+ adults: report of three cases and literature review. f Bone Miner Res 19: 714-721.

Essig, M., Duval, X., Al Kaied, F., Iordache, L., Gervais, A., Longuet, P. et al. (2007) Is phosphatemia the best tool to monitor renal tenofovir toxicity? F Acquir Immune Defic Syndr 46: $256-258$.

Feld, J.J., Wong, D.K. and Heathcote, E.J. (2009) Endpoints of therapy in chronic hepatitis B. Hepatology 49: 96-102.

Fletcher, R.H. and Fletcher, S.W. (2005) Treatment. In: Clinical Epidemiology: The Essentials, 4th edn. Philadelphia: Lippincott Williams \& Wilkins, pp. 125-145.

Foster, C., Lyall, H., Olmscheid, B., Pearce, G., Zhang, S. and Gibb, D.M. (2009) Tenofovir disoproxil fumarate in pregnancy and prevention of mother-to-child transmission of HIV-1: is it time to move on from zidovudine? HIV Med 10: 397-406.

Fux, C.A., Rauch, A., Simcock, M., Bucher, H.C., Hirschel, B., Opravil, M. et al. (2008) Tenofovir use is associated with an increase in serum alkaline phosphatase in the Swiss HIV Cohort Study. Antivir Ther 13: $1077-1082$.

Gallant, J.E., Staszewski, S., Pozniak, A.L., DeJesus, E., Suleiman, J.M., Miller, M.D. et al. (2004) Efficacy and safety of tenofovir DF vs stavudine in combination therapy in antiretroviral-naïve patients: a 3-year randomized study. FAMA 292: 191-201.

Garcia-Tsao, G., Parikh, C.R. and Viola, A. (2008) Acute kidney injury in cirrhosis. Hepatology 48: 2064-2067.

Giering, L.P. and Smith, J.E. (1995) Industrial perspective: from IND to NDA. $\mathcal{F}$ Nuclear Cardiology 2: 66-70.

Gitman, M.D., Hirschwerk, D., Baskin, C.H. and Singhal, P.C. (2007) Tenofovir-induced kidney injury. Expert Opin Drug Saf 6: 155-164.

Gupta, S.K. (2008) Tenofovir-associated Fanconi syndrome: review of the FDA Adverse Event Reporting System. AIDS Patient Care and STDs 22: 99-103.

Hanes, J.W., Zhu, Y., Parris, D.S. and Johnson, K.A. (2007) Enzymatic therapeutic index of acyclovir. Viral versus human polymerase gamma specificity. $\mathcal{F}$ Biol Chem 282: 25159-25167.

Heathcote, J., Gane, E.J., deMan, R.A., Sing, C., Sievert, W., Mauss, S. et al. (2008) Two year tenofovir disoproxil fumarate (TDF) treatment and adefovir dipivoxil (ADV) switch data en $\mathrm{HBeAg}$-positive patients with chronic hepatitis B (Study 103), preliminary analysis. Hepatology 48: 376A.
Hirt, D., Urien, S., Ekouevi, E.K., Rey, E., Arrive, E. and Blanche, S. (2009) Population pharmacokinetics of tenofovir in HIV-1-infected pregnant women and their neonates (ANRS 12109). Clin Pharmacol Ther 85: $182-189$.

Izzedine, H., Launay-Vacher, V. and Deray, G. (2005) Antiviral drug-induced nephrotoxicity. Am $\mathcal{F}$ Kidney Dis 45: 804-817.

Izzedine, H., Isnard-Bagnis, C., Hulot, J.S., Vittecoq, D., Cheng, A., Jais, C.K. et al. (2004) Renal safety of tenofovir in HIV treatment-experienced patients. AIDS 18: 1074-1076.

Jain, M.K., Comanor, L., White, C., Kipnis, P., Elkin, C., Leung, K. et al. (2007) Treatment of hepatitis B with lamivudine and tenofovir in HIV/ HBV-coinfected patients: factors associated with response. F Viral Hepat 14: 176-182.

Kaplowitz, N. (2001) Drug-induced liver disorders: implications for drug development and regulation. Drug Saf 24: 483-490.

Karras, A., Lafaurrie, M., Furco, A., Bourgarit, A., Droz, D., Sereni, D. et al. (2003) Tenofovir-related nephrotoxicity in human immunodeficiency virus-infected patients: three cases of renal failure, Fanconi syndrome, and nephrogenic diabetes insipidus. Clin Infect Dis 36: 1070-1073.

Kearney, B.P., Yale, K., Shah, J., Lijie, A. and Flaherty, J.F. (2006) Pharmacokinetics and dosing recommendations of tenofovir disoproxil fumarate in hepatic or renal impairment. Clin Pharmacokinet 45: 1115-1124.

Kinai, E. and Hanabusa, H. (2009) Progressive renal tubular dysfunction associated with long-term use of tenofovir DF. AIDS Res Hum Retroviruses 25: 387-394.

Kohler, J.J., Hosseini, S.H., Hoying-Brandt, A., Green, E., Johnson, D.M., Russ, R. et al. (2009) Tenofovir renal toxicity targets mitochondria of renal proximal tubules. Lab Invest 89: 513-519.

Kuo, A., Dienstag, J.L. and Chung, R.T. (2004) Tenofovir disoproxil fumarate for the treatment of lamivudine-resistant hepatitis B. Clin Gastroenterol Hepatol 2: 266-272.

Labarga, P., Barreiro, P., Martin-Carbonero, L., Rodriguez-Novoa, S., Solera, C., Medrano, J. et al. (2009) Kidney tubular abnormalities in the absence of impaired glomerular function in HIV patients treated with tenofovir. AIDS 23: 689-696.

Lacombe, K., Gozlan, J., Boyd, A., Boelle, P.Y., Bonnard, P., Molina, J.M. et al. (2008) Comparison of the antiviral activity of adefovir and tenofovir on hepatitis B virus in HIV-HBV-coinfected patients. Antivir Ther 13: 705-713.

Lebrecht, D., Venhoff, A.C., Kirschner, J., Wiech, T., Venhoff, N. and Walker, U.A. (2009) Mitochondrial tubulopathy in tenofovir disoproxil fumarate-treated rats. F Acquir Immune Defic Syndr 51: 258-263. 
Lee, H., Hanes, J. and Johnson, K.A. (2003) Toxicity of nucleoside analogues used to treat AIDS and the selectivity of the mitochondrial DNA polymerase. Biochemistry 42: 14711-14719.

Marcellin, P., Heathcote, E.J., Buti, M., Gane, E., de Man, R.A., Krastev, Z. et al. (2008) Tenofovir disoproxil fumarate versus adefovir dipivoxil for chronic hepatitis B. N Engl F Med 359: 2442-2455.

Matthews, G.V., Avihingsanon, A., Lewin, S.R., Amin, J., Rerknimitr, R., Petcharapirat, P. et al. (2008) A randomized trial of combination hepatitis $B$ therapy in $\mathrm{HIV} / \mathrm{HBV}$ coinfected antiretroviral naïve individuals in Thailand. Hepatology 48: 1062-1069.

McMahon, B.J. (2009) The natural history of chronic hepatitis B virus infection. Hepatology 49: S45-55.

Moyle, G. (2005) Mechanisms of HIV and nucleoside reverse transcriptase inhibitor injury to mitochondria. Antivir Ther 10(Suppl. 2): M47-52.

National Institute of Allergy and Infectious Diseases (2004) Division of AIDS Table for Grading the Severity of Adult and Pediatric Adverse Events (NIAID/DAIDS AE grading table). Available at: www3.niaid.nih.gov/labsAndResources/resources/ DAIDSClinRsrch/PDF/DAIDSAEGradingTable.pdf.

Nelson, M., Portsmouth, S., Stebbing, J., Atkins, M., Barr, A., Matthews, G. et al. (2003) An open-label study of tenofovir in HIV-1 and hepatitis B virus co-infected individuals. AIDS 17: F7-10.

Nuñez, M., Ramos, B., Diaz-Pollan, B., Camino, N., Martin-Cordero, L., Barreiro, P. et al. (2006) Virological outcome of chronic hepatitis $\mathrm{B}$ virus infection in HIV-coinfected patients receiving anti-HBV active antiretroviral therapy. AIDS Res Hum Retroviruses 22: 842-848.

Parsonage, M.J., Wilkins, E.G., Snowden, N., Issa, B.G. and Savage, M.W. (2005) The development of hypophosphatemic osteomalacia with myopathy in two patients with HIV infection receiving tenofovir therapy. HIV Med 6: 341-346.

Perrot, S., Aslangul, E., Szwebel, T., Caillat-Vigneron, N. and Le Jeunne, C. (2009) Bone pain due to fractures revealing osteomalacia related to tenofovirinduced proximal renal tubular dysfunction in a human immunodeficiency virus-infected patient. f Clin Rheumatol 15: 72-74.

Peters, M.G., Andersen, J., Lynch, P., Liu, T., AlstonSmith, B., Brosgart, C.L. et al. (2006) Randomized controlled study of tenofovir and adefovir in chronic hepatitis B virus and HIV infection: ACTG A5127. Hepatology 44: 1110-1116.

Peyriere, H., Reynes, J., Rouanet, I., Daniel, N., de Boever, C.M., Mauboussin, J.M. et al. (2004) Renal tubular dysfunction associated with tenofovir therapy. Report of 7 cases. F Acquir Immune Defic Syndr 35: 269-273.

Schmutz, G., Nelson, M., Lutz, T., Sheldon, J., Bruno, R., von Boemmel, F. et al. (2006) Combination of tenofovir and lamivudine versus tenofovir after lamivudine failure for therapy of hepatitis B in HIV-coinfection. AIDS 20: 1951-1954.

Schooley, R.T., Ruane, P., Myers, R.A., Beall, G., Lampiris, H., Berger, D. et al. (2002) Tenofovir DF in antiretroviral-experienced patients: results from a 48-week, randomized, double-blind study. AIDS 16: 1257-1263.

Sheldon, J., Camino, N., Rodés, B., Bartholomeusz, A., Kuiper, M., Tacke, F. et al. (2005) Selection of hepatitis B virus polymerase mutations in HIV-coinfected patients treated with tenofovir. Antivir Ther 10: 727-34.

Snow-Lampart, A., Chappell, B.J., Curtis, M., Zhu, Y., Heathcote, E.J., Marcellin, P. et al. (2008) Week 96 resistance surveillance for $\mathrm{HBeAg}$ positive and negative subjects with chronic HBV infection randomized to receive tenofovir DF $300 \mathrm{mg}$ qd. Hepatology 48: 745A.

Squires, K., Pozniak, A.L., Plerone, G., Steinhart, C.R., Berger, D., Bellos, N.C. et al. (2003) Tenofovir disoproxil fumarate in nucleoside-resistant HIV-1 infection. Ann Intern Med 139: 313-320.

Stephan, C., Berger, A., Carlebach, A., Lutz, T., Bickel, M., Klauke, S. et al. (2005) Impact of tenofovir-containing antiretroviral therapy on chronic hepatitis B in a cohort co-infected with human immunodeficiency virus. F Antimicrob Chemother 56: 1087-1093.

Stevens, J.L. and Baker, T.K. (2009) The future of drug safety testing: Expanding the view and narrowing the focus. Drug Discov Today 14: 162-167.

Tan, J., Degertekin, B., Wong, S.N., Husain, M., Oberhelman, K. and Lok, A.S. (2008) Tenofovir monotherapy is effective in hepatitis B patients with antiviral treatment failure to adefovir-resistant mutations. F Hepatol 48: 391-398.

Torres Isidro, M.V., Garcia Benayas, T., del Val Gomez Martinez, M., Gonzalez Gallardo, F., Pisonero, G., Castilla Miguel, S. et al. (2006) Role of bone gammagraphy in the diagnosis of secondary osteomalacia in a patient treated with tenofovir. Rev Esp Med Nucl 25: 103-106.

van Bömmel, F., Zöllner, B., Sarrazin, C., Spengler, U., Hüppe, D., Möller, B. et al. (2006) Tenofovir for patients with lamivudine-resistant hepatitis B virus (HBV) infection and high HBV DNA level during adefovir therapy. Hepatology 44: 318-325.

van Bömmel, F., Schernick, A., Hopf, U. and Berg, T. (2003) Tenofovir disoproxil fumarate exhibits strong antiviral effect in a patients with lamivudine-resistant severe hepatitis B reactivation. Gastroenterology 124: $586-587$

van Bömmel, F., Wünsche, T., Mauss, S., Reinke, P., Bergk, A., Schürmann, D. et al. (2004) Comparison of adefovir and tenofovir in the treatment of lamivudine-resistant hepatitis B virus infection. Hepatology 40: 1421-1415. 
Van Rompay, K.K., Brignolo, L.L., Meyer, D.J., Jerome, C., Tarara, R., Spinner, A. et al. (2004) Biological effects of short-term or prolonged administration of 9-[2-(phosphonomethoxy)propyl] adenine (tenofovir) to newborn and infant rhesus macaques. Antimicrob Agents Chemother 48: 1469-1487.

Venhoff, N., Setzer, B., Melkaoui, K. and Walker, U.A. (2007) Mitochondrial toxicity of tenofovir, emtricitabine and abacavir alone and in combination with additional nucleoside reverse transcriptase inhibitors. Antivir Ther 12: 1075-1085.

Verhelst, D., Monge, M., Meynard, J.L., Fouqueray, B., Mougenot, B., Girard, P.M. et al. (2002) Fanconi syndrome and renal failure induced by tenofovir: a first case report. Am J Kidney Dis 40: 1331.

Vidal, F., Domingo, J.C., Guallar, J., Saumoy, M., Cordobilla, B., Sánchez de la Rosa, R. et al. (2006) In vitro cytotoxicity and mitochondrial toxicity of tenofovir alone and in combination with other antiretrovirals in human renal proximal tubule cells. Antimicrob Agents Chemother 50: 3824-3832.

Viread. (2008) Package insert. Foster City, CA: Gilead Sciences.

Weinbaum, C.M., Mast, E.E. and Ward, J.W. (2009)

Recommendations for identification and public health management of persons with chronic hepatitis B virus infection. Hepatology 49: S35-44.

Woodward, C.L., Hall, A.M., Williams, I.G., Madge, S., Copas, A., Nair, D. et al. (2009)

Tenofovir-Associated renal and bone toxicity. HIV Med 10: 482-487.

Zhang, J., Zou, S. and Giulivi, A. (2001)

Epidemiology of hepatitis B in Canada. Can F Infect Dis 12: 345-350.
Visit SAGE journals online http://tag.sagepub.com

(SSAGEJOURNALS

Online 